\title{
HACCP and the Risk Assessment of Cold-chain
}

\author{
Zhang QingYing ${ }^{\mathrm{a},{ }^{* 1}}$, Chen Zhimin ${ }^{\mathrm{a},{ }^{* 2}}$ \\ ${ }^{a}$ Institute of Logistics Engineering, Wuhan University of Technology, Wuhan, China
}

\begin{abstract}
Considering that cold-chain involves lots of complicated operations which suffer from various uncertain factors during the process of implementing, it is inevitable to establish a sound and detailed risk assessment principle or means to guarantee the safety of cold-chain. HACCP, Hazard Analysis and Critical Control Point, is chosen to be a useful tool to analyze the processes of cold-chain, assess the potential risks for each operation link, and then identify the critical control points and give the appropriate risk weights, so as to ensure the safety, quality and reliability of the cold-chain.
\end{abstract}

Index Terms: Cold-chain; HACCP; Risk Assessment

(C) 2011 Published by MECS Publisher. Selection and/or peer review under responsibility of the Research Association of Modern Education and Computer Science

\section{Introduction}

The purpose of cold-chain is to ensure the quality of refrigerated and frozen items, and the core task is to keep foods transported at lower temperature. With strict time limits, the refrigerated and frozen items request higher and more complex transport manners and more rational organizations, which comparing with items transported at ambient temperatures. Therefore the extent of risk captured in each link determines the implementing effect of cold-chain. HACCP, Hazard Analysis and Critical Control Point, hold preventive concepts and identify possible risks at each link by qualitative analysis, and with the combining use of quantitative analysis to give the control limits for each risk. By means of identifying and assessing the existing risks, and taking appropriate measures, thus the effective operation of the cold-chain can be guaranteed [1].

\section{The Overview of Cold-chain}

Cold-chain is outlined a specific supply chain system, with perishable food purchased or fished from the origin places, the procedures of processing, storing, transporting, distributing and marketing are under required low temperature to ensure the safety, reduce losses and prevent pollution.

\footnotetext{
* Corresponding author:

| E-mail address: ${ }^{* 1} \underline{\text { Kathy8899@126.com; }}{ }^{* 2}$ Chenzhimin19880210@126.com
} 


\subsection{The processes analyze of the cold- chain}

According to the basic functions of logistics, cold-chain operations can be divided into the following four areas: supplement (producing, processing, purchasing, checking and accepting), storage (storing, loading, handling and sorting), transportation (transport, loading, handling and distribution) and consumption (transport, storing, sorting) [2]. The specific operation shows in Fig 1.

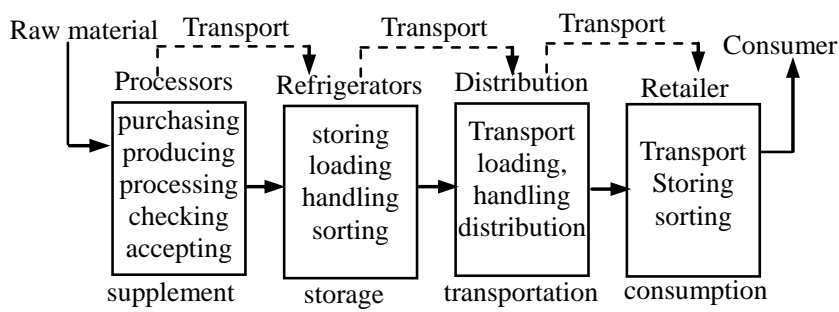

Fig. 1. Basic links in cold-chain

\subsection{The qualitative analysis of risks in all sectors of cold-chain}

\section{1) Supplement.}

This process includes four operations of producing, processing, purchasing, checking and accepting, the risks mainly contain the following:

a) To improve the appearance and extend the preservation period of products for making high profits, a variety of harmful additives are added in the process of producing.

b) Environmental pollution of origin points, deficiency of facilities and equipment used in cold-chain.

c) Lack of scientific technical guidances and safe supervision programs, the management in acceptance of raw materials is lax.

d) The existing safety standards and management technologtes are not completed, which is failure to ensure the safety of products.

\section{2) Storage.}

It includes processes of storing, loading, handling and sorting, the risks are mainly reflected in:

a) Short of necessary monitoring and management tools in response to mismatch between demand and supply.

b) cross-infection between products for unreasonable storage manners of different characteristics.

c) Damage, decay, pollution and reversal of the goods for the irrational stacking mode and location allocating pattern.

d) Illogically controll of temperature and dangerous working methods.

e) Loss and damage of goods due to stealing and careless work.

\section{3) Transportation.}

In this process the risks mainly includes:

a) Inappropriate transporting arrangement, the cold-chain products are easily contaminated by micro-organisms and harmful substances for long-distance transport.

b) Refrigeration requirement and safety measures are not carried out completed.

c) Improper selection of transporting equipments, which leading to safety issues.

d) Loss and damage of products during the periods of transporting. 


\section{4) Consumption.}

The main risks are:

a) Varies consumption needs and difficult sails management, which threaten the quality of products.

b) the cognition of specific cold-chain products is limited, consumers can not effectively protect themselves.

\section{The Use of HACCP to Quantitative Assess the Risks in Cold-chain}

\subsection{Intrinsic link between risk assessment and HACCP}

Risk assessment is defined as the quantitative evaluation of the event impacts on people's lives, property and others, which occurs before or after (but not over), in other words, it is the work of quantitative evaluating the possibility of loss. HACCP, Hazard Analysis and Critical Control Point, is used to identify hazards during the production of food, then take appropriate surveillance and control measures to prevent or reduce the occurring probability of harm. Therefore, to control the processes of cold-chain run safe, from the point of their definition, they two have some intrinsic link, by identifying risks or hazards, and take some control measures to reduce the negative impact on the final product.

\subsection{The necessity of HACCP in the risk assessment of cold-chain}

By degrade the processes of cold-chain, the existing risks of every process can be qualitative analyzed. Whether the cold-chain can be run accurately and efficiently is reflected in the degree of identification and control of risks. Not all the predictability risks are the root causes of harm, if take all the risks into the scope of operation, a lot of manpower, material resources and financial would occupied, and it is unrealistic in the actual operation either. Thus it is necessary to give a certain weight to every risk by quantitative methods. To access the harmful levels of risk for final products, the cold-chain can be run safe to a certain extent by monitoring the key risk. HACCP mainly consists of Hazard Analysis (HA) and critical control point (CCP), it can be used to describe the weight of each risk in the cold-chain, and determine the critical control points and controlled, thereby eliminating the harm or to lower the damage to an acceptable level.

\subsection{The steps of using HACCP to assess the size of risk in the cold-chain}

\section{1) Hazard analysis.}

Mainly qualitative analysis, with reference to GMP (Good Manufacturing Practice) and SSOP (Sanitation Standard Operating Procedure) and other quality management requirements. Considering four main operating: supplement, storage, transportation and consumption, from the biological, chemical and physical point of view to analyze potential hazards in each areas [3]. The results show in Table 1.

Table 1. The qualitative analysis of hazards in cold-chain

\begin{tabular}{ll}
\hline Chain of operations & \multicolumn{1}{c}{ Potential hazard } \\
\hline supplement & $\begin{array}{l}\text { dangerous additives, design mix and impurity; environmental pollution of origin points, deficiency of } \\
\text { facilities and equipment; lack of scientific technical guidance and safety supervision programs } \\
\text { cross-infection; damage, decay, pollution and reversal of the goods; Illogical controlling of temperature } \\
\text { and dangerous working methods; loss and damage of goods }\end{array}$ \\
\hline storage & $\begin{array}{l}\text { inappropriate transporting arrangement; improper selection of transporting equipments; Loss and } \\
\text { damage of products; cross-infection }\end{array}$ \\
\hline Transportation & Temperature controlling in consumer sites; cognition of consumers; \\
\hline
\end{tabular}




\section{2) Identify critical control points (CCP).}

The determination of critical control point is to know the critical point between safety and insecurity; food quality would be safe only when all the critical control points are controlled in the safe range [4]. To determine critical control points is the core of HACCP, therefore in the early planning stage, the selection of CCP should follow scientific methods, which shown in Fig 2.

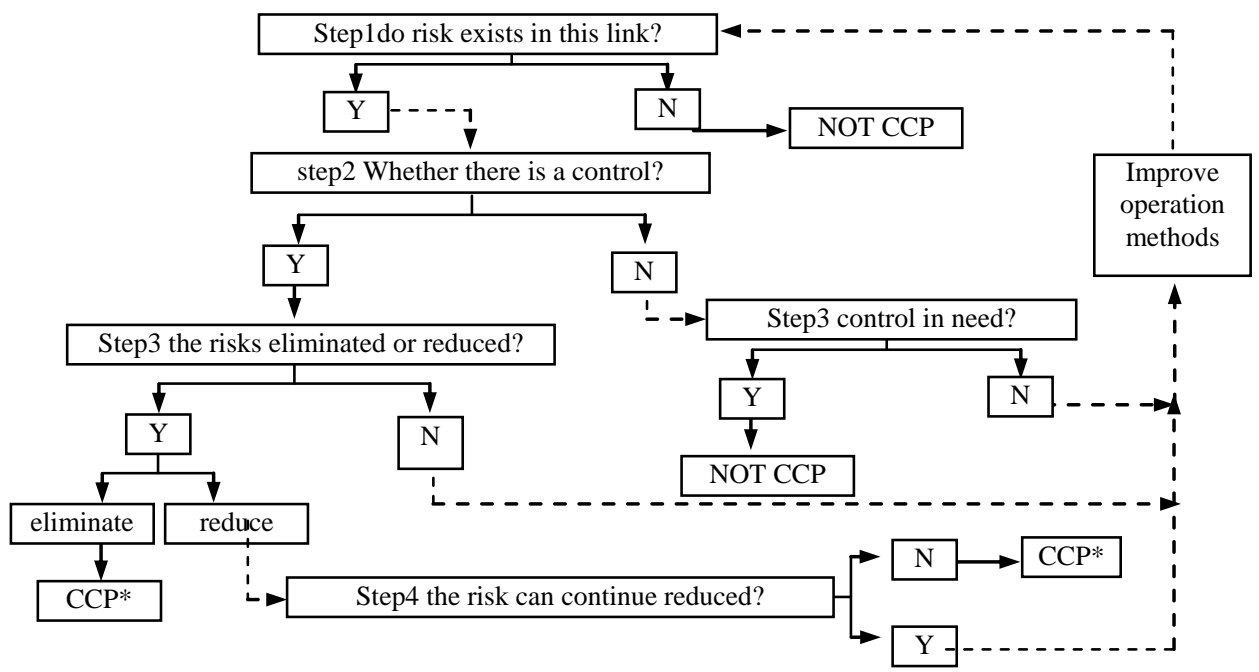

Fig. 2. The steps to determine the $\operatorname{CCP}(*)$

\section{3) Hazard analysis chart.}

The chart contains the evaluation weights of CCP. Monitoring and controlling parameters should be complete by HACCP groups with a strong sense of responsibility, and executives should review regularly to ensure monitoring is under predetermined plan. According to hazard analysis chart of key point (Table2), and further to evaluate the size of risk.

Table 2. Hazard analysis chart

\begin{tabular}{lllc}
\hline critical control points $(\mathbf{C C P})$ & Remarkable hazards & Critical limits & Risk weight \\
\hline $\begin{array}{l}\text { purchasing, checking and } \\
\text { accepting }\end{array}$ & $\begin{array}{l}\text { Qualities of raw materials; harmful virus and } \\
\text { bacterium. etc }\end{array}$ & national standard & $20 \%$ \\
Loading and handling & $\begin{array}{l}\text { bacterium duplicated; deteriorate and nasty } \\
\text { smell }\end{array}$ & $\begin{array}{l}\text { Working Instruction, } \\
\text { temperature and time }\end{array}$ & $15 \%$ \\
storing & $\begin{array}{l}\text { cross-infection; microorganism grows and } \\
\text { propagates; }\end{array}$ & $\begin{array}{l}\text { Corresponding storage } \\
\text { standards }\end{array}$ & \multicolumn{1}{c}{$15 \%$} \\
transport & $\begin{array}{l}\text { Dangerous working methods; microorganism } \\
\text { and chemical contamination }\end{array}$ & $\begin{array}{l}\text { real-time temperature } \\
\text { control system }\end{array}$ & $10 \%$ \\
sorting & $\begin{array}{l}\text { microorganism and chemical } \\
\text { contamination; cross-infection } \\
\text { chemical contamination; excessive additives } \\
\text { and bacterium implicated }\end{array}$ & expertise and the job \\
specifications & quality standard of goods & $20 \%$ \\
\hline
\end{tabular}

Of course, the risk weight of the critical control points vary with the implementation of food safety standards, advancement of the handling and transport equipments, improvements of storage facilities, enhancement of 
staff's professional quality and the actual choice selected by operators [5]. The weight coefficients also need to be repeated verified, modified and determined after executed a certain time. At this point, in the concrete implementation of cold-chain processes, by determine the risk weight of each critical control points, given the corresponding attention and allocate the appropriate of manpower, equipment, resources and funds, not only the safety operation of cold-chain guaranteed to a certain extent, the unreasonable allocation of resources, which result food problems eliminated ,either.

\section{Conclusion}

Cold-chain is a special form of logistics and a complex cryogenic system, which compose by a number of links, the overall processes from the procurement, processing, distribution, retail to consumption are all under lower temperature. In the safety management of cold-chain, HACCP from the three perspectives of biological, chemical and physical, combining qualitative and quantitative analysis methods to identify risks and assess weight of each risk, thereby to determine the critical control points and establish internal relations between hazards and risks.

\section{References}

[1] Huang Funan. Hazard Analysis and Critical Control Point [J]. Beijing: Food and Fermentation Industries. 2002, 28 (2), (in Chinese)

[2] Zhao Yanyan, Zhang Yu Yin. The application and optimization of HACCP system in the management of cold-chain logistics in China [J]. Anhui Agricultural Sciences. 2009, 37 (7), (in Chinese)

[3] Zhu Xiaoli, Zhu Yihua, Zhou Hong. HACCP based food safety management information system. JIANGSU AGRICULTURAL SCIENCES.2008, (6), (in Chinese)

[4] LIU Xiande, DUAN Qijia, SHE Ruiping. Problem Existing and Suggestions on Implementation and Establishment of HACCP System in China. FOOD SCIENCE.2007, 28(2), (in Chinese)

[5] Xu Xilin, Guo Siyuan, Li Lin and so on. Food Safety and HACCP [J]. Modern 'Chemical Industry, 2002, 22 (8), (in Chinese) 